Disponível em:

http://editora.unoesc.edu.br/index.php/race

RACE, Joaçaba, v. 16, n. 1, p. 95-120, jan./abr. 2017

\title{
INFLUENNCIA DO REFAZIMENTO DAS DEMONSTRAÇÕES CONTÁBEIS NO GERENCIAMENTO DE RESULTADOS DAS EMPRESAS LISTADAS NA BM\&FBOVESPA
}

Influence of the restatement of financial statements in earnings management of companies

listed on BM\&FBovespa

Paulo Roberto da Cunha

E-mail:pauloccsa@gmail.com

Doutor em Ciências Contábeis e Administração pela Universidade Regional de Blumenau; Mestre em Ciências Contábeis pela Universidade Regional de Blumenau; Professor na Universidade Regional de Blumenau no Programa de Pós-graduação em Ciências Contábeis.

Endereço para contato: Fundação Universidade Regional de Blumenau, Campus 1 Central, 89012-500, Blumenau, Santa Catarina, Brasil.

Leonardo Barbi Fernandes

E-mail:pauloccsa@gmail.com

Graduado em Ciências Contábeis pela Universidade do Estado de Santa Catarina.

Cristian Baú Dal Magro

E-mail: cristianbaumagro@gmail.com Mestre em Ciências Contábeis pela Universidade Regional de Blumenau; Doutorando em Ciências Contábeis e Administração pela Universidade Regional de Blumenau; Professor no Curso de Graduação em Contabilidade e Administração; Professor de Pós-graduação; Bolsista CAPES/CNPq vinculado ao Programa de Pós-graduação em Ciências Contábeis da Universidade Regional de Blumenau.

Artigo recebido em 28 de maio de 2015. Aceito em 04 de outubro de 2016. 
Resumo

A qualidade da informação contábil é essencial para os stakeholders, e a prática de gerenciamento de resultado é uma medida de qualidade da informação. Atrelada a isso, a Comissão de Valores Mobiliários (CVM) solicita a republicação das demonstrações contábeis sempre que julgar necessário. Contudo, no ato da republicação das demonstrações contábeis pode haver diferentes julgamentos em relação às escolhas contábeis por parte dos gestores, ocasionando modificações no nível de gerenciamento de resultados das organizações e assimetria informacional entre o principal e o agente. Desse modo, o objetivo com este estudo foi verificar a influência do refazimento das demonstrações contábeis no gerenciamento de resultados das empresas listadas na BM\&FBovespa. A análise ocorreu no período pré-refazimento, ano do refazimento e pósrefazimento. Realizou-se uma pesquisa descritiva, documental e com abordagem de cunho quantitativo. A amostra da pesquisa foi composta por 18 empresas com refazimento das demonstrações contábeis entre 1995 e 2012, e para fins de comparação foram selecionadas 18 empresas sem refazimento listadas na BM\&FBovespa que continham similaridades em relação ao tamanho e ao setor de atuação. Os resultados não revelam diferenças quanto à média dos accruals discricionários entre os períodos pré-refazimento, ano do refazimento e pósrefazimento. Por outro lado, os resultados em comparação com as empresas que não foram obrigadas ao refazimento das demonstrações contábeis revelam que o refazimento influencia o gerenciamento de resultado negativo. Diante das variáveis testadas, verificou-se que o endividamento influencia o gerenciamento de resultado negativo e que o tamanho da empresa influencia o gerenciamento de resultado positivo.

Palavras-chave: Refazimento das demonstrações contábeis. Gerenciamento de resultados. Qualidade da informação contábil.

Abstract

The quality of accounting information is essential for stakeholders and the practice of earnings management is a measure of quality of the information. Coupled to this, the Brazilian Securities Commission (CVM) requests the republication of the financial statements whenever necessary. However, upon republication of the financial statements may be different judgments about the financial choices by managers, resulting in changes in the level of earnings management organizations and informational asymmetry between the principal and the agent. Thus, the objective with this study was to investigate the influence of the restatement of financial statements in earnings management of companies listed on BM\&FBovespa. The analysis took place in the pre-restatement period, the year of restatement and post-restatement. We conducted a descriptive, documentary, with quantitative nature approach. The survey sample consisted of 18 companies with restatement of financial statements from 1995 to 2012 and for comparison 18 companies without restatement listed on BM\&FBovespa containing similarities in the size and sector of activity were selected. The results did not reveal differences from the average of 
discretionary accruals between the periods of pre-restatement, year of restatement and postrestatement. On the other hand, the results compared to companies that were not required to restate the financial statements reveal that the restatement influences the negative earnings management. Before the variables tested, it was found that the debt influences the negative earnings management and company size influences the positive earnings management.

Keywords: Restatement of financial statements. Earnings management. Quality of accounting information.

\section{INTRODUÇÃO}

O mercado financeiro nacional tem prezado pela transparência nas relações entre empresas e acionistas. Dessa forma, é necessário que as demonstrações contábeis divulgadas pelas companhias tenham um padrão de qualidade e transparência elevado, visto que é por meio desses relatórios financeiros que as empresas demonstram seu desempenho aos stakeholders (DECOURT et al., 2014).

Para aumentar o padrão de qualidade e transparência nas demonstrações contábeis, passou-se a exigir sua divulgação de acordo com o International Financial Reporting Standards (IFRS), coordenado pelo Comitê de Pronunciamentos Contábeis (CPC), por meio de seus pronunciamentos técnicos (JOIA; NAKAO, 2014). A convergência dos padrões contábeis nacionais para os padrões internacionais teve o objetivo de reduzir as distorções das informações divulgadas pelas empresas, podendo diminuir, assim, a assimetria informacional entre os diversos usuários da informação contábil (KLANN, 2011).

A assimetria informacional existente entre os usuários da informação contábil é relacionada ao conflito de interesses entre o principal e o agente, em que o detentor do controle pode tomar decisões de cunho pessoal que conflitem com a maximização de riqueza da companhia e dos acionistas, investidores/proprietários do capital (BAPTISTA, 2008). No conflito de interesses as pessoas podem aproveitar da liberdade e das brechas na legislação para atingirem seus objetivos pessoais. Assim, a possibilidade de utilizar a discricionariedade concede aos administradores liberdade na mensuração dos resultados (NARDI; NAKAO, 2009).

O resultado é um dos produtos mais utilizados pelo usuário da informação contábil para a formação de uma opinião acerca do desempenho da empresa. Contudo, o resultado é constituído por movimentações de natureza discricionária e, consequentemente, os gestores exercerão seu julgamento no reporte dessa informação (BARROS, 2012). Portanto, as escolhas contábeis que visam alterar os relatórios e 
a avaliação do desempenho e influenciar as relações contratuais são denominadas gerenciamento de resultados (PAULO, 2007).

Em contrapartida, existem as empresas que publicam demonstrações financeiras com deficiência informativa, que, por vezes, são obrigadas a corrigir os erros ou inconsistências pela republicação ou refazimento do documento correspondente (DANTAS et al., 2011). Dessa forma, destaca-se o papel dos órgãos reguladores e fiscalizadores das publicações das demonstrações contábeis, sendo a Comissão de Valores Mobiliários (CVM) a responsável no Brasil pelas companhias de capital aberto. Entre as atribuições do referido órgão está o poder de exigir, sempre que julgar necessário, a republicação e o refazimento das demonstrações (DANTAS et al., 2011).

A qualidade da informação contábil é essencial para os stakeholders, e a prática de gerenciamento de resultado é uma medida de qualidade da informação contábil. Atrelada a isso, a Comissão de Valores Mobiliários (CVM) solicita a republicação das demonstrações contábeis sempre que julgar necessário, como forma de melhorar a apresentação das demonstrações contábeis. Diante desse contexto, no ato da republicação das demonstrações contábeis pode haver diferentes julgamentos das escolhas contábeis por parte dos gestores, ocasionando modificações no nível de gerenciamento de resultados das organizações e assimetria informacional entre principal e agente.

Conforme a problematização apresentada, criou-se a seguinte pergunta de pesquisa: qual a influência do refazimento das demonstrações contábeis no nível de gerenciamento de resultados das empresas listadas na BM\&FBovespa? Assim, neste estudo teve-se como objetivo verificar a influência do refazimento das demonstrações contábeis no gerenciamento de resultados das empresas listadas na BM\&FBovespa. Para fins de comparabilidade, optou-se por verificar a influência do refazimento das demonstrações contábeis no gerenciamento de resultados em períodos distintos, quais sejam, pré-refazimento, ano do refazimento e pós-refazimento.

O estudo justifica-se na medida em que busca contribuir para a discussão da temática do gerenciamento de resultados na perspectiva do refazimento das demonstrações contábeis e da assimetria informacional entre principal e agente. Há diferentes estudos sobre o gerenciamento de resultados no Brasil, porém sua relação com o refazimento das demonstrações contábeis não tem sido abordada. Além disso, o estudo justifica-se pelo fato de que diferentes stakeholders utilizam as demonstrações financeiras publicadas para a tomada das decisões. Assim, ao identificar que há uma relação entre o gerenciamento de resultados e o refazimento das demonstrações contábeis, tal tomada de decisão pode ser afetada, podendo gerar assimetria de informação e conflitos de agência entre principal e agente. 


\section{FUNDAMENTAÇÃO TÉORICA}

\subsection{REFAZIMENTO/REPUBLICAÇÃO DAS DEMONSTRAÇÕES CONTÁBEIS}

A contabilidade deve ser avaliada pela capacidade de prover aos usuários informações úteis e confiáveis, reduzindo, assim, a possibilidade de assimetria informacional. No entanto, em certos casos, os responsáveis pela divulgação das demonstrações acabam manipulando as informações contábeis com o intuito de maximizar seus interesses pessoais ou da própria entidade, gerando informações tendenciosas que podem acarretar julgamentos enviesados por outros usuários (MURCIA; CARVALHO, 2007).

Nesse contexto, é fundamental a participação de órgãos reguladores em tal processo. No que se refere às companhias de capital aberto, o papel de regulamentar e fiscalizar a publicação das demonstrações contábeis é de responsabilidade da Comissão de Valores Mobiliários (CVM), entidade autárquica instituída pela Lei n. 6.385/76. De acordo com a Resolução CFC n. 737/92, é cabível a determinação de refazimento quando as demonstrações contábeis apresentem erros e/ou informações consideradas essenciais para seu perfeito entendimento, tenham sido divulgadas incompletas ou não tenham sido divulgadas (DANTAS et al., 2011).

A Deliberação CVM n. 388/01 passou a divulgar para todo o mercado os ofícios de refazimento expedidos, tornando públicas as causas que motivaram a determinação de refazimento ou republicação das demonstrações contábeis das companhias. Assim, a Comissão de Valores Mobiliários (CVM) divulga em seu sítio eletrônico os ofícios expedidos integralmente (DANTAS et al., 2011).

Teixeira, Politelo e Klann (2013) relatam que existe diferença entre a republicação e o refazimento das demonstrações contábeis. A republicação está atrelada a informações enviesadas, confusas ou incompletas, enquanto o refazimento inclui registros contábeis não realizados, cujas alterações modificam a situação patrimonial da empresa. Assim, a republicação apenas corrige informações, sem alterar a situação patrimonial, ao passo que o refazimento contempla correções que alteram a situação patrimonial da empresa. O refazimento geralmente ocorre em razão da expedição de ofícios pela Comissão de Valores Mobiliários e é acompanhado da republicação das demonstrações contábeis. 
O mercado pode reagir negativamente ao fato de uma companhia ser obrigada a refazer suas demonstrações contábeis, independente dos motivos apresentados (SILVA; RODRIGUES; SOUZA, 2012). A determinação de refazimento pode impactar a redução do valor da empresa, a redução da perspectiva de lucros futuros e a diminuição no preço das ações e afetar negativamente a confiança dos investidores (TEIXEIRA; POLITELO; KLANN, 2013). Por outro lado, o refazimento pode contribuir para diminuir a incerteza acerca do futuro da companhia.

As determinações de refazimento podem ser decorrentes, de modo geral, de erros involuntários, mas também de manipulações propositais nas informações contábeis. Portanto, é imprescindível a atuação fiscalizadora da Comissão de Valores Mobiliários (CVM) quanto ao cumprimento das normas vigentes no Brasil pelas companhias de capital aberto, preservando o direito de o investidor ter acesso a informações públicas fidedignas das empresas do mercado de capitais brasileiro (TEIXEIRA; POLITELO; KLANN, 2013).

Richardson, Tuna e Wu (2002) realizaram um estudo a respeito de uma amostra de empresas que republicaram suas demonstrações contábeis. O objetivo foi identificar se a prática de gerenciamento de resultados tinha relação com incentivos referentes ao mercado de capitais e incentivos contratuais. Os resultados indicaram que as pressões do mercado de capitais influenciam as empresas a adotarem políticas contábeis agressivas. Além disso, as informações contidas nos accruals podem ser relevantes para antecipar o gerenciamento de resultados nas empresas que republicaram suas demonstrações financeiras.

Wu (2002) estudou o comportamento do mercado em relação ao refazimento das demonstrações contábeis. O estudo analisou os dados de empresas que refizeram suas demonstrações nos anos 1977 e 2001. Os resultados mostram que houve uma reação fortemente negativa pelo mercado, representando uma acentuada queda nos preços das ações. Assim, as informações qualitativas e quantitativas dos ofícios de refazimento contribuíram negativamente para a resposta do mercado no curto prazo.

Baptista (2008) verificou se as demonstrações financeiras de empresas que foram objeto de refazimento/republicação possuem caráter informativo sobre a prática do gerenciamento de resultados. Os resultados indicaram que as práticas contábeis registradas nos ofícios sugerem que as empresas gerenciaram seus resultados a fim de alterar a expectativa dos usuários em relação ao futuro da companhia. Além disso, a situação econômica das entidades ajuda a explicar as manipulações, visto que apresentavam menor liquidez e rentabilidade, maior endividamento, maior concentração acionária e menores níveis de accruals e de risco, além de serem menores. 
Teixeira, Politelo e Klann (2013) analisaram os principais motivos de refazimento das demonstrações financeiras das companhias brasileiras de capital aberto. Como resultado demonstraram que o setor de consumo não cíclico possui o maior número de casos de refazimento. Os anos 2006 e 2008 apresentaram maior número de casos de refazimento, e o ano 2008 pode ter relação com a convergência às normas internacionais. Concluíram que a adoção das normas internacionais corroborou para o aumento do número de refazimentos de 2008 a 2012.

\subsection{GERENCIAMENTO DE RESULTADOS}

Os estudos sobre gerenciamento de resultados tiveram início na década de 1980, com os trabalhos seminais de Healy (1985), DeAngelo (1986) e Schipper (1989). Em 1991, Jones propôs um modelo diferenciado, visando controlar os efeitos das oscilações no ambiente econômico perante os accruals não discricionários pelas variações das receitas e do montante do imobilizado e diferido (JONES, 1991).

Em 1995, verificando a conjectura de que as receitas nem sempre são gerenciadas, Dechow, Sloan e Sweeney (1995) transformaram o modelo Jones (1991), o qual foi denominado modelo Jones Modificado. Em 1995, a fim de minimizar erros nas variáveis, Kang e Sivaramakrishnan (1995) propuseram variáveis explicativas para traduzir a realidade econômica da entidade, sendo chamado de modelo KS.

O gerenciamento de resultados é a intervenção proposital no processo de elaboração dos relatórios contábeis, ocasionado pelo julgamento dos administradores sobre as escolhas contábeis, com o intuito de obter algum benefício particular (SCHIPPER, 1989; HEALY; WAHLEN, 1999). Healy e Wahlen (1999) afirmam que o gerenciamento de resultado ocorre quando os administradores alteram as informações ou atividades operacionais, com o objetivo de alterar as informações financeiras ou passar uma imagem aos investidores que não corresponde à real situação da empresa.

Os gestores têm a possibilidade de escolha de diferentes procedimentos, sendo estes considerados igualmente válidos. Logo, abre-se espaço para que os administradores definam o conteúdo e a forma de divulgação, o momento e o método de mensuração, o valor de estimativas contábeis e de provisões orientadas à cobertura de perdas prováveis, e a classificação de valores mensurados (GOULART, 2007). Martinez (2001) comenta que “[...] o julgamento e o poder discricionário dos gerentes é tão importante que, muitas vezes, na realização de lançamentos contábeis, o fato mais importante para ser avaliado é a intenção.” 
Entretanto, o gerenciamento de resultados não é caracterizado como fraude contábil, mas é o exercício do julgamento dos administradores para influenciar seus demonstrativos financeiros (HEALY; WAHLEN, 1999). Para Martinez (2001), não se pode relacionar o gerenciamento de resultados com fraude, visto que este somente ocorre em razão de lacunas existentes na legislação contábil. Paulo (2007) estabelece que há distinção entre a manipulação da informação contábil e a contabilidade fraudulenta. A primeira é realizada pelo julgamento dos administradores acerca das escolhas de práticas contábeis dentro dos limites legais vigentes. A segunda representa as práticas adotadas que não estão dentro dos precedentes legais aceitos.

Os accruals discricionários são utilizados como proxy do gerenciamento de resultados. Assim, quanto maior o resultado dos accruals discricionários, mais evidente é a existência da prática de gerenciamento de resultados. Os accruals discricionários altamente positivos estão relacionados ao aumento do lucro para melhorar o resultado. Por outro lado, accruals discricionários negativos estão relacionados à intenção de reduzir o lucro ou diminuir o resultado (GOULART, 2007).

\section{PROCEDIMENTOS METOdOLÓGicos}

A pesquisa é caracterizada quanto aos objetivos como descritiva, pela identificação e descrição do nível de gerenciamento de resultado das empresas com refazimento das demonstrações contábeis e seu inter-relacionamento. Em relação aos procedimentos, é caracterizada como documental por utilizar materiais que não receberam tratamento específico e que podem ser reelaborados. Quanto à abordagem do problema, a pesquisa é definida como quantitativa pelo uso de técnicas estatísticas para investigar a relação entre o nível de gerenciamento de resultados e o refazimento das demonstrações contábeis.

\subsection{POPULAÇÃO E AMOSTRA}

A população da pesquisa foi constituída pelas empresas que tiveram ofício de refazimento das demonstrações contábeis expedido pela Comissão de Valores Mobiliários. Para a seleção da amostra foram consideradas as empresas em que o ofício exigia o refazimento das demonstrações financeiras padronizadas (DPFs), desconsiderando as empresas com ofício de refazimento das informações trimestrais (Itr) e os formulários de informações anuais (Ian). 
Após a seleção das empresas com refazimento das demonstrações financeiras padronizadas (DPFs), foram selecionadas as empresas com refazimento por improbidades no reconhecimento e/ou mensuração nas contas do ativo, passivo, patrimônio líquido e resultado. Assim, inicialmente a amostra foi constituída de 25 empresas que atenderam aos critérios estabelecidos.

Além disso, as empresas Banco Cruzeiro do Sul S.A., Inepar Energia S.A., Parmalat Brasil S.A. Indústria de Alimentos, Varig S.A., Hotéis Othon S.A., Telecomunicações Brasileiras S.A. - Telebras e CPM S.A. foram excluídas da pesquisa porque não dispuseram de todas as informações para a estimação dos accruals discricionários por meio do modelo KS (KANG; SIVARAMAKRISHNAN, 1995), restando uma amostra de 18 empresas.

Para fins de comparação do gerenciamento de resultado das empresas com refazimento das demonstrações financeiras padronizadas (DFP), foram selecionadas 18 empresas listadas na BM\&FBovespa que continham similaridades em relação ao tamanho e ao setor de atuação. Os critérios foram os seguintes: as empresas não poderiam ter ofícios de refazimento expedidos pela Comissão de Valores Mobiliários (CVM); foi observado o valor do ativo total das empresas; e buscaram-se os valores mais próximos entre as empresas no ano em que a empresa da amostra em comparação foi exigida ao refazimento.

O Quadro 1 demonstra a amostra da pesquisa, delimitando as empresas obrigadas ao refazimento e as selecionadas para a elaboração da análise comparativa, com seus respectivos setores.

Quadro 1 - Amostra da pesquisa

\begin{tabular}{|c|c|c|c|}
\hline $\begin{array}{l}\text { Empresas objeto de refazi- } \\
\text { mento }\end{array}$ & Empresas comparativas & Ano & Segmento \\
\hline Pronor Petroquímica S.A. & Unipar Carbocloro S.A. & 2000 & Petroquímicos \\
\hline Sifco S.A. & Metalúrgica Duque S.A. & 2000 & Artefatos de ferro e aço \\
\hline Josapar S.A. & Conservas Oderich S.A. & 2000 & Alimentos diversos \\
\hline \multirow{3}{*}{ Siderúrgica J.L. Aliperti S.A. } & \multirow{3}{*}{ Fibam Companhia Industrial } & 1999 & \multirow{3}{*}{ Artefatos de ferro e aço } \\
\hline & & 2000 & \\
\hline & & 2001 & \\
\hline Cerâmica Chiarelli S.A. & $\begin{array}{l}\text { Haga S.A. Indústria e Co- } \\
\text { mércio }\end{array}$ & 2005 & Materiais de construção \\
\hline $\begin{array}{l}\text { Investimentos e Participações em } \\
\text { Infraestrutura S.A. - INVEPAR }\end{array}$ & $\begin{array}{l}\text { Concessionária Rod. Osório - } \\
\text { Porto Alegre S.A. - CONCEPA }\end{array}$ & 2005 & Exploração de rodovias \\
\hline
\end{tabular}




\begin{tabular}{|c|c|c|c|}
\hline $\begin{array}{l}\text { Empresas objeto de refazi- } \\
\text { mento }\end{array}$ & Empresas comparativas & Ano & Segmento \\
\hline $\begin{array}{l}\text { Mendes Júnior Engenharia } \\
\text { S.A. }\end{array}$ & Construtora Sultepa S.A. & 2006 & Construção pesada \\
\hline \multirow{2}{*}{ Café Solúvel Brasília S.A. } & \multirow{2}{*}{ Cia Cacique de Café Solúvel } & 2006 & \multirow{2}{*}{ Café } \\
\hline & & 2007 & \\
\hline $\begin{array}{l}\text { Manufatura de Brinquedos } \\
\text { Estrela S.A. }\end{array}$ & Tec Toy S.A. & 2009 & Brinquedos e jogos \\
\hline $\begin{array}{l}\text { Telecomunicações Brasileiras } \\
\text { S.A. - Telebras }\end{array}$ & Ideiasnet S.A. & 2011 & Programas e serviços \\
\hline $\begin{array}{l}\text { BAESA - Energética Barra } \\
\text { Grande S.A. }\end{array}$ & $\begin{array}{l}\text { EMAE - Empresa Metropoli- } \\
\text { tana de Águas e Energias S.A. }\end{array}$ & 2011 & Energia elétrica \\
\hline $\begin{array}{l}\text { Companhia Estadual de Dis- } \\
\text { tribuição de Energia Elétrica } \\
\text { CEEE - GT }\end{array}$ & $\begin{array}{l}\text { Companhia Energética do } \\
\text { Maranhão (CEMAR) }\end{array}$ & 2012 & Energia elétrica \\
\hline $\begin{array}{l}\text { Companhia Estadual de Gera- } \\
\text { ção e Transmissão de Energia } \\
\text { Elétrica CEEE - D }\end{array}$ & Rio Grande Energia S.A. & 2012 & Energia elétrica \\
\hline $\begin{array}{l}\text { Inepar S.A. Indústria e Cons- } \\
\text { truções }\end{array}$ & Indústrias Romi S.A. & 2009 & Máq. e equip. Industriais \\
\hline Marfrig Alimentos S.A. & JBS S.A. & 2011 & Carnes e derivados \\
\hline Minerva S.A. & JBS S.A. & 2011 & Carnes e derivados \\
\hline $\begin{array}{l}\text { DTCOM - Direct To Company } \\
\text { S.A. }\end{array}$ & CSU Cardsystem S.A. & 2011 & Serviços diversos \\
\hline
\end{tabular}

Fonte: os autores.

Observando o Quadro 1, a empresa JBS S.A., classificada como comparativa, foi selecionada para duas empresas objetos de refazimento distintas, a Marfrig 
Alimentos S.A. e a Minerva S.A., ambas no ano 2011. Dessa forma, a amostra da pesquisa final corresponde a um total de 35 empresas.

\subsection{HIPÓTESES DA PESQUISA}

Para a elaboração do estudo foram delineadas hipóteses de pesquisa. Nesse sentido, o estudo de Baptista (2008) verificou a relação do gerenciamento de resultados com variáveis do refazimento das demonstrações contábeis e as variáveis de controle endividamento, tamanho e variação das vendas. Verificando por um prisma diferente deste estudo, Baptista (2008) indica que empresas com maior e menor endividamento são propensas às práticas de gerenciamento de resultados. Além disso, identificou que o refazimento das demonstrações contábeis pode ser utilizado como proxy do gerenciamento de resultados. Com base na evidência, foi elaborada a hipótese geral:

H1: O refazimento das demonstrações contábeis, o endividamento, o tamanho e a variação das vendas influenciam o nível de gerenciamento de resultado das empresas.

Richardson, Tuna e Wu (2002) apontam que as empresas que refizeram suas demonstrações contábeis estão envolvidas em manipulações intencionais, logo, espera-se que apresentem níveis de gerenciamento de resultados maiores do que aquelas que não refizeram suas demonstrações contábeis, destacando-se a seguinte hipótese:

H1a: O refazimento das demonstrações contábeis influencia o nível de gerenciamento de resultado das empresas.

A variável endividamento é frequentemente utilizada nos estudos sobre gerenciamento de resultados, em que as empresas mais endividadas tendem a gerenciar os resultados buscando aumentar os lucros (WATTS; ZIMMERMAN, 1990; SHLEIFER; VISHNY, 1997; COELHO; LOPES, 2007). Para tanto, formulou-se a seguinte hipótese:

H1b: O endividamento influencia o nível de gerenciamento de resultado das empresas. 
Nardi e Nakao (2009) consideraram a variável tamanho da empresa relacionada ao nível de gerenciamento de resultados. Mencionam que o tamanho é positivamente relacionado com o gerenciamento de resultados, uma vez que empresas maiores têm incentivos para reduzir custos políticos. Portanto, foi estabelecida a seguinte hipótese:

H1c: O tamanho influencia o nível de gerenciamento de resultado das empresas.

Por fim, o estudo de Klann (2011) buscou identificar, além de outras variáveis, se a variável crescimento das vendas impacta os níveis de gerenciamento de resultados das empresas brasileiras e inglesas. Identificou que nas empresas brasileiras existe uma relação entre o crescimento das vendas e o gerenciamento de resultados. Nesse contexto, tem-se a seguinte hipótese:

H1d: A variação das vendas influencia o nível de gerenciamento de resultado das empresas.

\subsection{COLETA E ANÁLISE DOS DADOS}

As informações referentes à obrigação de refazimento das demonstrações contábeis foram obtidas por meio dos ofícios expedidos pela CVM, expostos em seção específica no sítio eletrônico. Os dados para a seleção das empresas utilizadas de comparação às obrigadas ao refazimento das demonstrações contábeis foram consultados por meio do sítio eletrônico da CVM.

As demonstrações contábeis utilizadas para o cálculo dos accruals discricionários, endividamento, tamanho e variação das vendas foram obtidas por meio dos dados fornecidos pelas empresas no sítio da CVM. Essas informações foram registrados em planilhas eletrônicas de acordo com o ano correspondente. A coleta de dados foi realizada entre os meses de setembro e novembro de 2014, e o modelo para a verificação do nível de (accruals discricionários) gerenciamento de resultados nos períodos pré-refazimento, refazimento e pós-refazimento foi o KS (KANG; SIVARAMAKRISHNAN, 1995).

Para a análise dos dados, primeiramente foi verificado o nível de gerenciamento de resultados das empresas com refazimento das demonstrações contábeis para o período de um ano anterior à exigência do refazimento (pré-refazimento), para o período da exigência do refazimento (refazimento), e para o período de um ano posterior 
ao refazimento (pós-refazimento), e também das empresas comparativas com o intuito de elaborar todas as comparações estimadas pelo estudo. O modelo KS (KANG; SIVARAMAKRISHNAN, 1995) foi utilizado para estimar o nível de gerenciamento de resultados; e a Equação 1 demonstra o modelo.

$$
\begin{aligned}
& A T_{i t}=\emptyset_{0}+\emptyset_{1}\left[\delta_{1} \operatorname{Rec}_{i t}\right]+\emptyset_{2}\left[\delta_{2} \text { Desp }_{i t}\right]+\emptyset_{3}\left[\delta_{3} A t . I m o b_{i t}\right]+\varepsilon_{i t} \\
& A D_{i t}=A T_{i t}-\left\{\emptyset_{0}+\emptyset_{1}\left[\delta_{1} \operatorname{Rec}_{i t}\right]+\emptyset_{2}\left[\delta_{2} \text { Desp }_{i t}\right]+\emptyset_{3}\left[\delta_{3} A t . I m o b_{i t}\right]\right\}
\end{aligned}
$$

Em que:

$$
\begin{aligned}
& A T_{\text {it }}=\text { Acumulações Totais }=\left(C G L-\text { Depreciação \& Amortização } o_{t}\right) \\
& A T_{\text {it }}=\text { Acumulações Totais }=\left(C G L-\text { Depreciação \& Amortização } o_{t}\right) \\
& \text { Rec }_{\text {it }}=\text { Receita Líquida (excluindo tributação) } \\
& \text { Desp }_{\text {it }}=\text { Custos e Despesas operacionais antes da Depreciação \& Amortização } \\
& C G L=\text { Capital de Giro Líq.excluindo as disp., fin. de C.P e Prov. Impostos a pagar } \\
& \text { At. Imob }{ }_{i t}=\text { Ativo Imobilizado e Intangivel } \\
& \text { C.Receber } r_{i, t-1}=\text { Contas a Receber no período } t-1 \\
& \text { Depreci, }_{i-1}=\text { Despesas de Depreciação } \\
& \delta_{1}=C \cdot \text { Receber }_{i, t-1} / \text { Rec }_{i, t-1} \\
& \delta_{2}=\left(\Delta C G-C \cdot \text { Receber }_{i t}\right) / \text { Desp }_{i, t-1} \\
& \delta_{3}=\text { Deprec }_{i, t-1} / A \cdot \operatorname{Imob}_{i, t-1}
\end{aligned}
$$

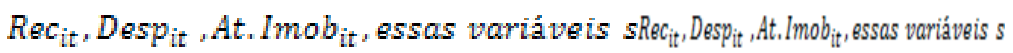

Essas variáveis são escaladas em termos de ativos totais.

Destaca-se que o modelo KS permite extrair as informações diretamente das contas do balanço patrimonial, para buscar explicar a dimensão dos accruals totais. A variável AT (accruals totais) é constituída pela variação do capital de giro líquido, sendo esse saldo escalonado pelos ativos totais (MARTINEZ, 2008). A Rec é representada pela receita líquida excluída dos impostos sobre vendas, medida em termos de porcentagem dos ativos totais. A Desp é representada pelo total de despesas operacionais, incluindo CMV, CPV, despesas de vendas e despesas administrativas, escalonadas pelos ativos totais (MARTINEZ, 2008). 
A variável A.Imob é representada pelo valor do ativo permanente, escalonada pelos ativos totais. Os parâmetros $\delta 1, \delta 2$ e $\delta 3$ podem ser interpretados como os indicadores de rotatividade que procuram acomodar fatores específicos e compensam o fato de o modelo KS estimar a amostra conjunta de várias empresas (cross-sectional). $\mathrm{O}$ indicador $\delta 1\left[\delta_{1}=\right.$ C. Receber $_{i, t-1} / \operatorname{Rec}_{i, t-1}$ $\delta_{1}=C$. Receber $\left._{i, t-1} / \operatorname{Rec}_{i, t-1}\right]$ representa a razão entre contas a receber e receitas do ano anterior, multiplicada pelas vendas do período [ $\delta_{1} x \operatorname{Rec}_{i t}$ $\left.\delta_{1} x \operatorname{Rec}_{i t}\right]$. O indicador $\delta 2\left[\delta_{2}=\left(C G_{i, t-1}-\right.\right.$ C. Receber Rect-1 $\left._{i, t}\right) /$ Desp $_{i, t-1}$ $\delta_{2}=\left(C G_{i, t-1}-C\right.$. Receber $\left._{i, t-1}\right) /$ Desp $_{i, t-1}$ ] representa a razão entre o capital de giro líquido e as despesas operacionais do período anterior, multiplicada pelas despesas operacionais do período $\left[\delta_{2} x \operatorname{Desp}_{i t}\right]\left[\delta_{2} x \operatorname{Desp}_{i t}\right]$. Por fim, o $\delta 3 \quad\left[\delta_{3}=\right.$ Deprec $_{i, t-1} /$ A.Imob $\left._{i, t-1}\right] \delta_{3}=$ Deprec $_{i, t-1} /$ A. Imo $\left._{i, t-1}\right]$ constitui a razão entre as despesas de depreciação e os ativos imobilizados do período anterior, multiplicada pelo ativo imobilizado do período [ $\delta_{3} x \mathrm{~A} \cdot \mathrm{Imob}_{i t}$ ] $\left.\delta_{3} x \mathrm{~A} . \mathrm{Imob}_{i t}\right]$ (MARTINEZ, 2008).

Em seguida, foi utilizado o teste de médias ANOVA por meio do Statistical Package for the Social Sciences (SPSS), somente com a amostra de empresas com refazimento. O intuito foi avaliar a existência de diferença no nível de (accruals discricionários) gerenciamento de resultados entre os períodos pré-refazimento, ano do refazimento e pós-refazimento. Considerou-se o número 1 como variável dos accruals discricionários do ano do pré-refazimento, o número 2 como variável dos accruals discricionários para o ano do refazimento e o número 3 como variável dos accruals discricionários para o ano do pós-refazimento.

Por fim, para verificar a existência de influência do refazimento das demonstrações contábeis e das variáveis endividamento, tamanho e a variação das vendas no nível de gerenciamento de resultados das empresas foi utilizada a regressão linear múltipla, exposta pela Equação 2:

$$
\text { Accrual Discr }=\beta_{0}+B_{1} \text { Reap }+B_{2} \text { Envid }+B_{3} L N T a m+B_{4} \text { Var Vendas }+\varepsilon
$$

Em que: 
Accrual Discr = Consideraram-se os accruals de todas empresas que republicaram suas demonstrações contábeis nos respectivos períodos e os accruals discricionários das empresas comparativas; os accruals discricionários foram obtidos mediante o erro da Equação 1;

Reap = variável dummy 1 para empresas que reapresentaram suas demonstrações contábeis e 0 para as empresas comparativas que não haviam a representação;

Endiv = nível de endividamento geral das empresas;

LN Tam = Logaritmo natural do tamanho (ativo total);

Var Vendas = Variação das receitas líquidas com vendas pela Equação 3.

Var. Vendas $=\left(\frac{\text { Receita líquida } a_{1}}{\text { Receita líquida } a_{t-1}}\right)-1=\left(\frac{\text { Receita líquida }}{t 1}\right)-1$

\section{ANÁLISE DOS RESULTADOS}

Primeiramente foram identificadas as empresas listadas na BM\&FBovespa obrigadas, por meio de ofício expedido pela Comissão de Valores Mobiliários (CVM), ao refazimento das demonstrações financeiras. A Tabela 1 mostra a segregação das empresas obrigadas ao refazimento por setores.

\begin{tabular}{lrr} 
Tabela 1 - Refazimentos por setor da BM\&FBovespa & \\
\hline \multicolumn{1}{c}{ Setores } & Quantidade & \% \\
\hline Consumo não cíclico & 10 & 25 \\
Materiais básicos & 8 & 20 \\
Construção e transporte & 6 & 15 \\
Utilidade pública & 6 & 15 \\
Consumo cíclico & 4 & 10 \\
Bens industriais & 3 & 7,5 \\
Tecnologia da Informação & 2 & 5 \\
Financeiro e outros & 1 & 2,5 \\
Total & 40 & 100 \\
\hline Fonte: os autores. & &
\end{tabular}

Verifica-se que existe predominância para as empresas do setor de consumo não cíclico ao refazimento das demonstrações contábeis, ou seja, 25\% das empresas obrigadas ao refazimento das demonstrações financeiras são desse setor. As empresas que pertencem aos setores de materiais básicos, utilidade pública, construção e transporte e consumo 
cíclico possuem uma parcela significativa da amostra, somando, respectivamente, 20\%, 15\%, 15\% e 10\%. Dessa forma, os cinco setores correspondem a 85\% da amostra total.

Para verificar o nível de gerenciamento de resultados nos períodos pré-refazimento, ano do refazimento e pós-refazimento foi utilizado o modelo KS. A Tabela 2 mostra os accruals discricionários das empresas obrigadas ao refazimento das demonstrações contábeis.

Tabela 2 - Accruals discricionários das empresas com refazimento das demonstrações contábeis

\begin{tabular}{|c|c|c|c|c|}
\hline \multirow{2}{*}{ Empresas } & \multirow{2}{*}{$\begin{array}{l}\text { Período do } \\
\text { refazimento }\end{array}$} & \multicolumn{3}{|c|}{ Accruals discricionários } \\
\hline & & Pré & Refaz. & Pós \\
\hline \multirow{3}{*}{ Siderúrgica J.L. Aliperti S.A. } & 1999 & 0,5881 & 0,6700 & 0,8874 \\
\hline & 2000 & 0,5888 & 0,6699 & 0,9899 \\
\hline & 2001 & 0,6600 & 0,7783 & 1,1213 \\
\hline Josapar S.A. & 2000 & 0,3013 & 0,4406 & 0,4629 \\
\hline Pronor Petroquímica S.A. & 2000 & 0,3752 & 0,4444 & 0,7857 \\
\hline Sifco S.A. & 2000 & 0,2489 & 0,2845 & 0,3825 \\
\hline Cerâmica Chiarelli S.A. & 2005 & $-0,2112$ & $-1,4792$ & $-1,5863$ \\
\hline Excelsior Alimentos S.A. & 2005 & 0,0815 & 0,2088 & 0,4196 \\
\hline $\begin{array}{l}\text { Investimentos e Participações em Infraes- } \\
\text { trutura S.A. }\end{array}$ & 2005 & 0,4712 & 0,5616 & 0,8813 \\
\hline Café Solúvel Brasília S.A. & $\begin{array}{l}2006 \\
2007\end{array}$ & $\begin{array}{r}-4,8420 \\
-4,8223\end{array}$ & $\begin{array}{l}-4,7292 \\
-6,1841\end{array}$ & $\begin{array}{l}-5,9344 \\
-7,9931\end{array}$ \\
\hline Mendes Júnior Engenharia S.A. & 2006 & $-0,0615$ & 0,4718 & 0,6220 \\
\hline Manufatura de Brinquedos Estrela S.A. & 2009 & $-0,5782$ & $-0,5765$ & $-0,8322$ \\
\hline Inepar S.A. Indústria e Construções & 2009 & 0,2135 & 0,1256 & 0,5228 \\
\hline DTCOM Direct To Company S.A. & 2011 & $-0,2805$ & $-0,5189$ & $-0,9163$ \\
\hline Marfrig Alimentos S.A. & 2011 & 0,3910 & 0,3397 & 0,4283 \\
\hline Minerva S.A. & 2011 & 0,7741 & 0,7823 & 0,8867 \\
\hline BAESA Energética Barra Grande S.A. & 2012 & 0,4879 & 0,5734 & 0,8019 \\
\hline $\begin{array}{l}\text { Companhia Est. de Ger. e Transm. de } \\
\text { Energia Elétrica }\end{array}$ & 2012 & $-0,1185$ & 0,0821 & 0,0424 \\
\hline $\begin{array}{l}\text { Companhia Est. de Distribuidora de } \\
\text { Energia Elétrica }\end{array}$ & 2012 & 0,6234 & 0,6884 & 0,5788 \\
\hline
\end{tabular}

Fonte: os autores.

Nota: Pré = Período do pré-refazimento, refaz. = Período do refazimento e Pós = Período do pós-refazimento. 
Verifica-se na Tabela 2 que as empresas Minerva S.A. (2011), Siderúrgica J.L. Aliperti S.A. (2001) e Companhia Estadual de Distribuição de Energia Elétrica (2012) apresentaram maior nível de gerenciamento de resultado positivo no ano de obrigação do refazimento das demonstrações contábeis, respectivamente com 0,7823, 0,7783 e 0,6884. Por outro lado, a empresa Café Solúvel Brasília S.A. (2006 e 2007) apresentou maior nível de gerenciamento de resultado negativo, para reduzir seu lucro ou aumentar seus prejuízos nos anos do refazimento das demonstrações contábeis, respectivamente com -4,7292 e -6,1841.

No ano do pré-refazimento, as empresas que mais gerenciaram resultado positivamente foram Minerva S.A. (2011), Siderúrgica J.L. Aliperti S.A. (2001) e Companhia Estadual de Distribuição de Energia Elétrica (2012), ou seja, as mesmas que gerenciaram resultado no ano do refazimento das demonstrações contábeis, inclusive na mesma ordem. A diferença é que no pré-refazimento o nível estimado de accruals discricionários foi inferior ao ano do refazimento, sendo de 0,7741 para a empresa Minerva S.A., de 0,6600 para a empresa Siderúrgica J.L. Aliperti S.A. e de 0,6234 para a Companhia Estadual de Distribuição de Energia Elétrica. Ao analisar o gerenciamento negativo no ano do pré-refazimento a empresa que mais gerenciou resultado foi Café Solúvel Brasília S.A. (2006 e 2007), respectivamente com accruals discricionários estimados de -4,8420 e -4,8223.

No período do pós-refazimento, a empresa Siderúrgica J.L. Aliperti S.A. apresentou os maiores níveis de gerenciamento de resultado positivo para os anos estudados, ou seja, com accruals discricionários estimados respectivamente de 0,8874, 0,9899 e 1,1213. O maior nível de gerenciamento de resultado negativo no período do pós-refazimento se manteve com a empresa Café Solúvel Brasília S.A., com -7,9931 e -5,9344 de accruals discricionários.

No ano do pré-refazimento, a empresa Mendes Júnior Engenharia S.A. foi a que menos gerenciou resultado, obtendo accruals discricionários de -0,0615. No ano do refazimento, a Companhia Estadual de Geração e Transmissão de Energia Elétrica teve accrual discricionário estimado em 0,0821, sendo a empresa que menos gerenciou resultado. No período do pós-refazimento, novamente a empresa Companhia Estadual de Geração e Transmissão de Energia Elétrica foi a que menos gerenciou resultado, com accrual discricionário de 0,0424.

Após a análise descritiva foi verificado se existe diferença significativa entre os accruals discricionários estimados para os períodos pré-refazimento, ano do refazimento e pós-refazimento. Assim, existem três possibilidades para a realização de comparações: período do pré-refazimento versus ano do refazimento; período do pré- 
-refazimento versus período do pós-refazimento; e ano do refazimento versus período do pós-refazimento. Para a realização das comparações, aplicou-se o teste de médias ANOVA, conforme a Tabela 3.

Tabela 3 - Resultado do teste ANOVA para comparações dos períodos

\begin{tabular}{|c|c|c|c|c|c|c|}
\hline \multirow{2}{*}{ (I) $\mathrm{V} 2$} & \multirow{2}{*}{ (J) $\mathrm{V} 2$} & \multirow{2}{*}{$\begin{array}{c}\text { Diferença } \\
\text { média (I-J) }\end{array}$} & \multirow{2}{*}{ Erro padrão } & \multirow{2}{*}{ Sig. } & \multicolumn{2}{|c|}{ Intervalo de confiança $95 \%$} \\
\hline & & & & & Limite inferior & Limite superior \\
\hline \multirow{2}{*}{1} & 2 & 0485939, & ,5230756, & 996 & $-1,260066$ & 1,357254 \\
\hline & 3 & 0995894 & ,5230756 & ,982 & $-1,209071$ & 1,408250 \\
\hline \multirow{2}{*}{2} & 1 &,- 0485939 & ,5230756 & ,996 & $-1,357254$ & 1,260066 \\
\hline & 3 & ,0509954 &, 5230756 & 995 & $-1,257665$ & 1,359656 \\
\hline \multirow{2}{*}{3} & 1 &,- 0995894 & ,5230756 & 982 & $-1,408250$ & 1,209071 \\
\hline & 2 &,- 0509954 & 5230756, & 995 & $-1,359656$ & 1,257665 \\
\hline
\end{tabular}

Fonte: os autores.

Nota: 1 - Accruals discricionários ano do pré-refazimento; 2 - Accruals discricionários ano do refazimento; e 3 - accruals discricionários ano do pós-refazimento.

Verifica-se na Tabela 3 que não foram encontradas diferenças significativas entre as médias de accruals discricionários dos períodos (pré-refazimento, ano do refazimento e pós-refazimento). Os níveis de significância do teste ANOVA foram superiores a 5\%, confirmando a hipótese de que as médias de todos os grupos são iguais. Dessa forma, conclui-se que não existe diferença no nível de gerenciamento de resultado das empresas em períodos pré-refazimento, ano do refazimento e pós-refazimento das demonstrações contábeis.

Diante do resultado, é possível evidenciar que mesmo que as empresas sejam obrigadas ao refazimento das demonstrações contábeis, seus gestores continuam aplicando as mesmas escolhas contábeis, não alterando o nível de gerenciamento de resultados apresentado diante da republicação. Dessa forma, é possível questionar a utilidade do refazimento das demonstrações contábeis na diminuição da assimetria informacional e dos conflitos de agência.

Por fim, foi verificado se há confirmação da hipótese de pesquisa, que visa identificar a influência do refazimento e das variáveis de controle endividamento, tamanho e variação das vendas no nível de gerenciamento de resultados das empresas. Para tanto, os accruals discricionários foram considerados como variável dependente, e as variáveis independentes foram o refazimento das demonstrações contábeis, caracterizadas pela dummy 1 para as empresas com refazimento e 0 para as empresas comparativas sem refazimento, o endividamento calculado para ambos grupos de em- 
presas, o tamanho caracterizado pelo Log Natural do Ativo total para ambos grupos de empresas e a variação das vendas para ambos grupos de empresas.

Anteriormente à apresentação dos resultados da regressão linear múltipla entre as variáveis utilizadas, foi preciso estabelecer o $\mathrm{R}^{2}$ e o teste de Durbin-Watson que é utilizado para verificar a presença de autocorrelação nos resíduos em uma regressão linear. A Tabela 4 demonstra os coeficientes de relacionamento entre as variáveis.

Tabela 4 - Resumo dos testes da regressão linear múltipla

\begin{tabular}{rrrrr}
\hline Modelo & R & R quadrado & R quadrado ajustado & Erro padrão da estimativa \\
\hline 1 &, $932 \mathrm{a}$ &, 869 &, 855 &, 38096 \\
\hline
\end{tabular}

Fonte: os autores.

Verifica-se na Tabela 4 que o modelo de regressão apresenta um $\mathrm{R}^{2}$ no valor de 0,869, ou seja, as variáveis independentes (refazimento, endividamento, tamanho e variação das vendas) explicam a variável dependente (accruals discricionários) em 86,9\%. A Tabela 5 mostra o nível de significância para o modelo de regressão linear previamente proposto. A análise é realizada para verificar se a variação explicada é suficientemente forte para justificar uma regressão. Em outros termos, realiza comparação entre variação explicada e variação não explicada (residual) (CUNHA; COELHO, 2007).

Tabela 5 - Resultados do modelo de regressão linear múltipla

\begin{tabular}{llrrrrr}
\hline \multicolumn{2}{l}{ Modelo } & Soma dos quadrados & df & Quadrado médio & Z & \multirow{2}{*}{ Sig. } \\
\hline \multirow{2}{*}{1} & Regressão & 35,630 & 4 & 8,908 & 61,378 &, $000 \mathrm{~b}$ \\
& Resíduo & 5,370 & 37 &, 145 & & \\
& Total & 41,000 & 41 & & & \\
\hline Fonte:
\end{tabular}
Fonte: os autores.

Observa-se na Tabela 5 que o modelo de regressão linear múltipla, considerando a variável dependente (accruals discricionários), as variáveis explicativas (refazimento dos demonstrativos contábeis, endividamento, tamanho (ativo total) e a variação das vendas), apresentou significância ao nível de 1\% (sig. 0,000). Assim, rejeita-se a hipótese nula e, consequentemente, admite-se que existe influência das variáveis explicativas sobre a variável dependente.

Por fim, foi elaborado o teste de Kolmogorov-Smirnov para identificar a normalidade dos resíduos. Conforme Cunha e Coelho (2007), o conjunto dos resíduos produzidos deve demonstrar distribuição normal. Essa normalidade mostra que os casos se apresentam normalmente em toda a extensão da população. A Tabela 6 mostra o teste de normalidade Kolmogorov-Smirnov para o modelo em estudo. 
Tabela 6 - Teste de normalidade Kolmogorov-Smirnov

\begin{tabular}{llr}
\hline & & Residual despadronizado \\
\hline $\mathrm{N}$ & Média & 42 \\
Parâmetros normais & Desvio padrão &, 362 \\
& Absoluto &, 134 \\
Diferenças mais extremas & Positivo &, 134 \\
& Negativo &,- 109 \\
Kolmogorov-Smirnov Z & &, 868 \\
Sig. assint. (duas caudas) & &, 439 \\
Sig. exata (duas extremidades) & &, 404 \\
Probabilidade de ponto & &, 000 \\
\hline Fonte: os autores.
\end{tabular}

Fonte: os autores.

Verifica-se na Tabela 6 que o resultado do teste de normalidade foi de 0,404 , ou seja, maior que 0,05. Esse resultado rejeita a hipótese nula, dessa forma, os dados seguem uma distribuição normal. Por fim, são apresentadas as variáveis explicativas significantes para a influência na variável dependente, conforme a Tabela 7.

Tabela 7 - Resultado das relações entre variáveis consideradas no modelo de regressão linear múltipla

\begin{tabular}{|c|c|c|c|c|c|c|c|c|}
\hline & \multirow{2}{*}{ Modelo } & \multicolumn{2}{|c|}{$\begin{array}{c}\text { Coeficientes não } \\
\text { padronizados }\end{array}$} & $\begin{array}{l}\text { Coeficientes } \\
\text { padronizados }\end{array}$ & \multirow{2}{*}{ t } & \multirow{2}{*}{ Sig. } & \multicolumn{2}{|c|}{ Estatísticas de colinearidade } \\
\hline & & B & $\begin{array}{l}\text { Modelo } \\
\text { padrão }\end{array}$ & Beta & & & Tolerância & VIF \\
\hline 1 & $\begin{array}{l}\text { (Cons- } \\
\text { tante) }\end{array}$ & $\begin{array}{r}1,167 \mathrm{E}- \\
10\end{array}$ & ,059 & & ,000 & 1,000 & & \\
\hline & Ref &,- 103 & ,061 &,- 103 & $-1,701$ & ,097 & 962 & 1,039 \\
\hline & End &,- 898 & ,060 &,- 898 & $-14,901$ & 000 & ,975 & 1,025 \\
\hline & Tam & 149 & ,061 & 149 & 2,443 & ,019 & 952 & 1,051 \\
\hline & Var &,- 022 & 062 &,- 022 &,- 360 & ,721 & ,924 & 1,083 \\
\hline
\end{tabular}

Fonte: os autores.

Neste estudo foi considerado um nível de significância de 10\% para relacionar as variáveis independentes com a variável dependente. Dessa maneira, a Tabela 
7 mostra que somente a variável variação nas vendas (Var) não apresentou influência sobre o gerenciamento de resultados, rejeitando a hipótese H1d.

A variável refazimento das demonstrações contábeis (Ref) apresentou nível de significância de 0,097, estando praticamente no limite do nível de significância estabelecido. Dessa forma, é possível inferir que o refazimento das demonstrações contábeis exerce influência sobre o gerenciamento de resultado negativo $(-0,103)$, confirmando a hipótese da H1a.

A variável endividamento (End) apresentou nível de significância em 1\% (0,0000), confirmando a hipótese H1b, ou seja, o maior endividamento influencia o gerenciamento de resultado negativo. Por fim, a variável tamanho (Tam) possui nível de significância de 0,019, em que o maior tamanho influência o gerenciamento de resultado positivo, aceitando a hipótese H1c.

Conforme os resultados expostos, as hipóteses H1a, H1b e H1c foram aceitas, e a hipótese H1d foi rejeitada. Os resultados alinham-se às inferências de Wu (2002), em que as empresas obrigadas ao refazimento ficam com má impressão sobre a qualidade da informação contábil por parte do mercado. Para tanto, conforme os resultados deste estudo, as empresas com refazimento tendem a gerenciar com menor intensidade os dados contábeis para a obtenção de resultados positivos. Esse fato é coerente porque empresas que visam obter maior confiabilidade pelo mercado tendem a adotar políticas contábeis mais conservadoras, com vistas a recuperar a credibilidade do mercado financeiro.

Por fim, tem-se que o maior endividamento é relacionado com o menor gerenciamento de resultados. Esse achado complementa as inferências de Baptista (2008), em que as empresas exercem suas forças para um menor nível de accruals discricionários quando estão mais endividadas. Além disso, é verificado que as empresas, quando republicam seus balanços, apresentam menor nível de accruals discricionários. Esse achado sugere que as práticas contábeis registradas antes do refazimento poderiam estar tendendo para um maior gerenciamento de resultados (BAPTISTA, 2008).

De maneira geral, os resultados são suportados pela teoria da agência, em que foram encontradas evidências de que o refazimento das demonstrações contábeis diminui a assimetria de informações entre o principal e o agente, pelo fato de que o refazimento influenciou para o gerenciamento de resultados negativos. Além disso, os resultados indicam que a qualidade da informação diante do gerenciamento de resultados negativos é melhorada com o refazimento das demonstrações contábeis. 


\section{CONCLUSÃO}

O presente estudo teve o objetivo de verificar a influência do refazimento das demonstrações contábeis no gerenciamento de resultados das empresas listadas na BM\&FBovespa, verificando essa influência nos períodos pré-refazimento, ano do refazimento e pós-refazimento. Foram identificadas as empresas listadas na BM\&FBovespa que apresentaram refazimento no período de 1995 a 2012. Assim, foram consideradas para o estudo as empresas obrigadas ao refazimento/republicação pelos motivos de improbidades no reconhecimento e/ou mensuração de contas do ativo, passivo, patrimônio líquido e contas de resultado no período de 1995 a 2012.

Os resultados sugerem que nos períodos do pré-refazimento as empresas Minerva S.A., Siderúrgica J.L. Aliperti S.A. e Companhia Estadual de Distribuição de Energia Elétrica foram as que mais gerenciaram resultados positivamente. Já a empresa Café Solúvel Brasília S.A. apresentou maior nível de gerenciamento de resultado negativo no período do pré-refazimento.

No ano do refazimento, as empresas que apresentaram maior nível de gerenciamento para resultado positivo foram Minerva S.A., Siderúrgica J.L. Aliperti S.A. e Companhia Estadual de Distribuição de Energia Elétrica. Contudo, a empresa que no ano do refazimento apresentou maior nível de gerenciamento para resultado negativo foi Café Solúvel Brasília S.A. No período do pós-refazimento a empresa que apresentou maior nível de gerenciamento para resultado positivo foi a Siderúrgica J.L. Aliperti S.A. No entanto, no período do pós-refazimento, a empresa que apresentou maior nível de gerenciamento para resultado negativo foi Café Solúvel Brasília S.A.

Os achados revelam que não há diferenças entre as médias de accruals discricionários entre os períodos pré-refazimento, ano do refazimento e pós-refazimento. Conclui-se que mesmo as empresas sendo obrigadas ao refazimento das demonstrações contábeis, seus gestores ainda aplicam em períodos posteriores as mesmas escolhas contábeis para o reporte dos demonstrativos contábeis.

Além disso, os resultados indicam que o refazimento exerce influência sobre o gerenciamento de resultado negativo $(-0,103)$, o maior endividamento influencia o gerenciamento de resultado negativo $(-0,898)$, e o maior tamanho influencia o gerenciamento de resultado positivo $(0,149)$. Por fim, a variação das vendas não apresentou influência sobre o gerenciamento de resultado.

Conclui-se que em um teste observando apenas os accruals discricionários das empresas com refazimento, um ano antes do ano do refazimento (pré-refazimento) e um ano após o refazimento (pós-refazimento) não foram encontradas diferenças 
significativas ao nível de 5\%. Assim, não houve gerenciamento de resultado superior ou inferior para essas empresas pelos motivos do refazimento. Por outro lado, em um comparativo entre as empresas com refazimento em relação às que não foram obrigadas à mesma exigência, foi observado que o refazimento influencia o gerenciamento de resultado negativo, o endividamento influencia o gerenciamento de resultado negativo, e o tamanho influencia o gerenciamento de resultado positivo. Diante das hipóteses estabelecidas tem-se que as hipóteses H1a, H1b e H1c foram aceitas e a hipótese H1d foi rejeitada.

\section{REFERÊNCIAS}

BAPTISTA, E. M. B. Análise do perfil das empresas brasileiras segundo o nível de gerenciamento de resultados. 2008. 303 p. Tese (Doutorado em Administração)-Universidade Federal do Rio Grande do Sul, Porto Alegre, 2008.

BARROS, C. M. E. Gerenciamento de Resultados contábeis e a qualidade de Governança Corporativa: Um estudo empírico em empresas brasileiras de capital aberto. 2012. 148 p. Dissertação (Mestrado em Ciências Contábeis)-Universidade Federal do Paraná, Curitiba, 2012.

COELHO, A. C. D.; LOPES, A. B. Avaliação da prática de gerenciamento de resultados na apuração de lucro por companhias abertas brasileiras conforme seu grau de alavancagem financeira. Revista de Administração Contemporânea, v. 11, n. 2, p. 121-144, 2007. Edição Especial.

CUNHA, J. V. A.; COELHO, A. C. Regressão linear múltipla. In: CORRAR, L. J.; PAULO E.; DIAS FILHO, J. M. (Coord.). Análise multivariada: para cursos de administração, ciências contábeis e economia. São Paulo: Atlas, 2007.

DANTAS, J. A. et al. Determinações de refazimento/republicação de demonstrações financeiras pela CVM: O papel dos auditores independentes. Revista Universo Contábil, v. 7, n. 2, p. 45-64, 2011.

DEANGELO, L. E. Accounting numbers as market valuation substitutes: A study of management buyouts of public stockholders. The Accounting Review, v. 61, i. 3, p. 400-420, 1986.

DECHOW, P. M.; SLOAN, R. G.; SWEENEY, A. P. Detecting earnings management. The Accounting review, v. 70, i. 2, p. 193-225, 1995. 
DECOURT, R. F. et al. Existe Gerenciamento de Resultados nas empresas com ações negociadas na BM\&FBovespa? In: CONGRESSO ANPCONT, 8., 2014, Rio de Janeiro. Anais... Rio de Janeiro, 2014.

GOULART, A. M. C. Gerenciamento de resultados contábeis em instituições financeiras no Brasil. 2007. 219 p. Tese (Doutorado em Ciências Contábeis)-Universidade de São Paulo, São Paulo, 2007.

HEALY, P. M. The effect of bonus schemes on accounting decisions. Journal of Accounting and Economics, v. 7, i. 1, p. 85-107, 1985.

HEALY, P. M.; WAHLEN, J. M. A review of the earnings management literature and its implications for standard setting. Accounting Horizons, v. 13, i. 4, p. 365-383, 1999.

JOIA, R. M.; NAKAO, S. H. Adoção de IFRS e gerenciamento de resultado nas empresas brasileiras de capital aberto. Revista de Educação e Pesquisa em Contabilidade (REPeC), v. 8, n. 1, 2014.

JONES, J. J. Earnings management during import relief investigations. Journal of Accounting Research, p. 193-228, 1991.

KANG, S. H.; SIVARAMAKRISHNAN, K. Issues in testing earnings management and an instrumental variable approach. Journal of Accounting Research, v. 33, i. 2, p. 353-367, 1995.

KLANN, R. C. Gerenciamento de Resultados: Análise comparativa de empresas brasileiras e inglesas antes e após adoção das IFRS. 2011. 372 p. Tese (Doutorado em Ciências Contábeis)-Universidade Regional de Blumenau, Blumenau, 2011.

MARTINEZ, A. L. Detectando earnings management no Brasil: estimando os accruals discricionários. Revista de Contabilidade e Finanças, São Paulo: Universidade de São Paulo, v. 19, n. 46, p. 7-17, 2008.

MARTINEZ, A. L. Gerenciamento dos Resultados Contábeis: Estudo empírico das companhias abertas brasileiras. 2011. 167 p. Tese (Doutorado em Ciências Contábeis)-Universidade de São Paulo, São Paulo, 2011.

MURCIA, F. D. R.; CARVALHO, L. N. Conjecturas Acerca do Gerenciamento de Lucros, Republicação das Demonstrações Contábeis e Fraude Contábil. Contabilidade Vista \& Revista, v. 18, n. 4, p. 61-82, 2007. 
NARDI, P. C. C.; NAKAO, S. H. Gerenciamento de resultados e a relação com o custo da dívida das empresas brasileiras abertas. Revista Contabilidade \& Finanças, v. 20, n. 51, p. 77-100, 2009.

PAULO, E. Manipulação das informações contábeis: Uma análise teórica e empírica sobre os modelos operacionais de detecção de gerenciamento de resultados. 2007. 269 p. Tese (Doutorado em Ciências Contábeis)-Universidade de São Paulo, São Paulo, 2007.

RICHARDSON, S. A.; TUNA, A.; WU, M. Predicting earnings management: The case of earnings restatements. Min, Predicting Earnings Management: The Case of Earnings Restatements, Oct. 2002.

SCHIPPER, K. Commentary on earnings management. The Accounting Horizons, v. 3, i. 4, p. 91-102, 1989.

SHLEIFER, A.; VISHNY, R. W. A survey of corporate governance. The Journal of Finance, v. 52, i. 2, p. 737-783, 1997.

SILVA, C. A. T.; RODRIGUES, F. F.; SOUZA, L. M. Influência da Determinação de Refazimento/Republicação no Preço das Ações. In: CONGRESSO USP DE CONTROLADORIA E CONTABILIDADE, 12., 2012, São Paulo. Anais... São Paulo, 2012.

TEIXEIRA, S. A.; POLITELO, L.; KLANN, R. C. Fatores relacionados ao refazimento das demonstrações contábeis das companhias brasileiras de capital aberto. In: ENCONTRO NACIONAL DE CURSOS DE GRADUAÇÃO EM ADMINISTRAÇÃO, 24., 2013, Florianópolis. Anais... Florianópolis, 2013.

WATTS, R. L.; ZIMMERMAN, J. L. Positive accounting theory: a ten-year perspective. The Accounting Review, v. 65, i. 1, p. 131-156, 1990.

WU, M. Earnings restatements: A capital market perspective. 2002. 


\section{Como citar este artigo:}

ABNT

DAL MAGRO, Cristian Baú; CUNHA, Paulo Roberto da, FERNANDES, Leonardo Barbi. Influência do refazimento das demonstrações contábeis no gerenciamento de resultados das empresas listadas na BM\&FBovespa. RACE, Revista de Administração, Contabilidade e Economia, Joaçaba: Ed. Unoesc, v. 16, n. 1, p. 95-120, jan./abr. 2017. Disponível em: <http://editora.unoesc.edu.br/index.php/race>. Acesso em: dia/mês/ano.

APA

Dal Magro, C. B., Cunha, P. R. da, \& Fernandes, L. B. (2017). Influência do refazimento das demonstrações contábeis no gerenciamento de resultados das empresas listadas na BM\&FBovespa. RACE, Revista de Administração, Contabilidade e Economia, 16(1), 95-120. Recuperado em dia/mês/ano, de http://editora.unoesc.edu. br/index.php/race 